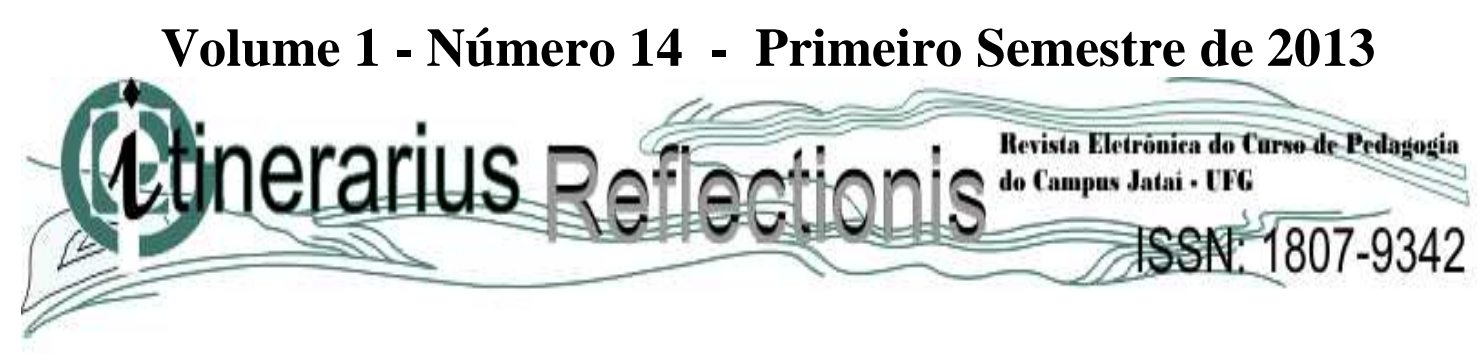

EDUCAÇÃO E COMPUTADORES

\title{
Os softwares educacionais, um novo estilo educativo em busca de um novo paradigma.
}

\author{
Valéria Leite Oliveira Costa. \\ Pedagoga pela Universidade Católica de Goiás. \\ Pós-Graduada em Informática em Educação na UFLA. \\ valerialoc@gmail.com
}

Resumo: Este artigo tem como objetivo sintetizar sobre a explanação da diversidade de programas educacionais que podem auxiliar o professor no processo de ensino, mais precisamente na educação infantil. As novas formas de ensinar o aluno, de maneira lúdica e prazerosa, os software nos perpassam novos caminhos para facilitar o ensino na fase infantil. O enfoque maior desse estudo está voltado para a criança com déficit de aprendizagem, que utilizando os novos recursos tecnológicos, os softwares educacionais, tornam-se uma poderosa ferramenta de ensino/aprendizagem facilitando o trabalho do professor e buscando recuperar a autoestima destas crianças.

Palavras-chave: Educação infantil; ensino-aprendizagem; software educacional.

Abstract: This article aims to make a brief explanation of the diversity of educational programs that can assist the teacher in teaching, more precisely in early childhood education. The new ways of teaching the student, so playful and pleasurable, the software in new ways permeate to facilitate teaching in the infant stage. The major focus of this study is aimed at children with learning disabilities, that using new technological features educational software becomes a powerful tool for teaching / learning facilitating the teacher's work and recover the self-esteem of these children.

Key-word: Early childhood education, teaching and learning, educational software. 


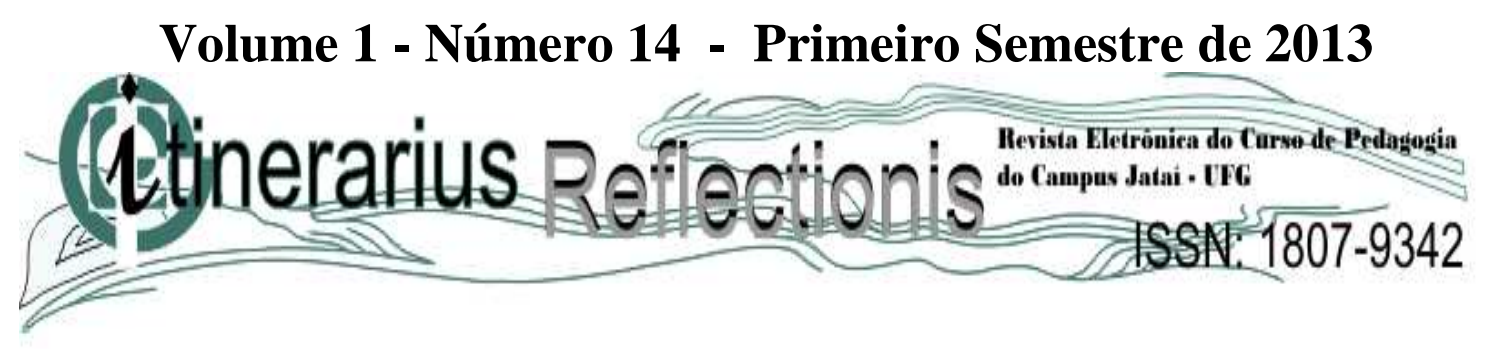

Considerações preliminares.

O tema aqui proposto está ligado profundamente com minha formação acadêmica, e experiência enquanto professora de uma escola pública. Pedagoga, habilitada em Administração Escolar, especialista na área de Informática em Educação. Minhas experiências em sala de aula me fizeram refletir sobre a questão da computação vinculada à aprendizagem, principalmente a Educação Infantil. Sabendo da importância que os diversos meios tecnológicos existentes na atualidade exercem sobre nossa sociedade contemporânea, percebi, no meu caminhar como educadora e pesquisadora, que a informática é sem dúvida uma importante ferramenta para o desenvolvimento da educação e da escola, sobretudo na educação infantil, mas que precisa ser discutida, estudada e analisada. A informática, de modo especial o softwares educacionais, podem ser sem dúvida uma perspectiva de transformações e mudanças na vida dos educandos, mais precisamente na educação infantil. Assim sendo, este artigo tem a intenção de proporcionar, ainda que modestamente, uma nova maneira de ensinar, na qual o software, seja visto, como uma ferramenta de apoio ao professor no processo educativo, quando utilizado com eficiência e criatividade. De modo que, o objetivo desse estudo foi analisar a contribuição que os softwares podem proporcionar na viabilidade do processo de ensino aprendizagem, principalmente na educação infantil, enquanto ferramenta eficaz e complementar. A problemática levantada foi analisar as vantagens que os softwares oferecem para o ensino aprendizagem. 


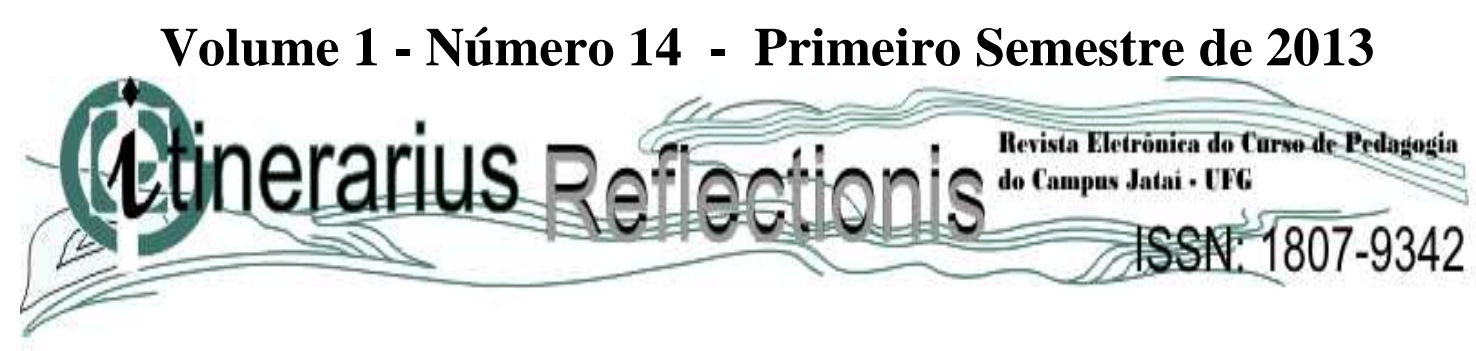

EDUCAÇÃO E COMPUTADORES

\section{Os Softwares educacionais, um novo estilo educativo em busca de um novo paradigma.}

A utilização de técnicas para auxiliar nas atividades do dia-a-dia não é dádiva de nossa atualidade, pois a milhares de anos o homem busca meios para facilitar seu trabalho. Um exemplo disso foi à criação do "ábaco" instrumento utilizado pelos povos - gregos, fenícios, chineses entre outros - para contar e fazer cálculo matemático.

Com o passar dos anos e o desenvolvimento das ciências somando as diversas áreas, principalmente Telecomunicações e Informática proporcionou um novo enfoque para a construção do conhecimento. Com a implementação da rede mundial de computadores, a internet, e com a vulgarização dos computadores pessoais, a "informação" passou a estar disponível a todos os usuários, tornando-se uma poderosa ferramenta de pesquisa.

Hodiernamente é quase que impossível imaginar a nossa vida sem o computador, a internet, os celulares e diversas outras formas de tecnologia que a cada dia é lançada no mercado.

O sistema educacional não poderia deixar de incorporar os novos recursos tecnológicos, ampliando o conhecimento e buscando a informação, por meio dos computadores, que estão inseridos nas escolas como ferramenta de auxilio aos professores na execução de tarefas e atividades educacionais e, assim, enriquecendo a prática pedagógica e ao mesmo tempo, auxiliando os alunos na construção do conhecimento, sobretudo, das crianças que apresentam déficit de aprendizagem, pois podem auxiliá-las na fixação dos conteúdos desenvolvidos em sala de aula.

Segundo dados apresentados, pela revista Nova Escola (2008. p.32), Maria 


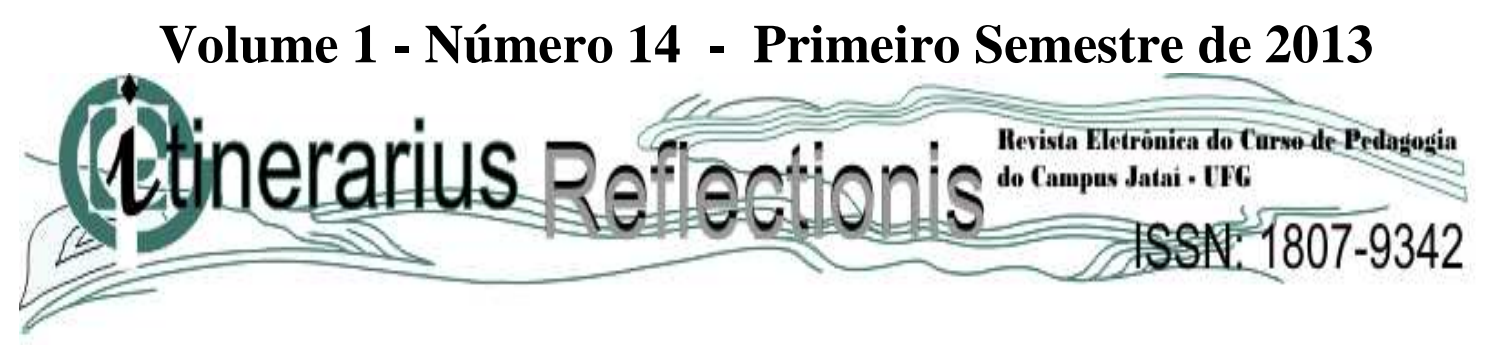

Montessori defende que "o caminho do intelecto passa pelas mãos, porque é por meio do movimento e do toque que as crianças exploram e decodificam o mundo ao seu redor". Sendo assim, o professor deve prepara atividades motivadoras partindo do concreto rumo ao abstrato, pois o aluno que em determinado momento teve dificuldade na aquisição do conhecimento, quando o professor apresentou a informação de forma abstrata, pode no computador desenvolve-las com mais facilidade, pois os programas dão às crianças a possibilidade de interação com as informações apresentada pelo professor.

Segundo os estudos de Vygotsky (1984), é por meio da interação com o adulto que a criança desenvolve o seu conhecimento. O referido autor, ao escrever a teoria da zona de desenvolvimento proximal, "o desenvolvimento proximal é a distância entre o nível de desenvolvimento real e o nível de desenvolvimento potencial do indivíduo" (VYGOTSKY, 1984, p. 168), informa que o nível real é o conhecimento que a criança já tem, ou seja, aquilo que a criança consegue fazer sem a ajuda de outro. O nível potencial é o conhecimento que a criança pode vir a adquirir com a intervenção do professor mediador, por meio da linguagem, material cultural e até mesmo dos softwares educacionais. Assim, o professor intervém e auxilia na construção e reelaboração do conhecimento do aluno.

De acordo com as reflexões de Valente (1993), o papel do professor neste processo é o de mediador da aprendizagem, é o aluno e não mais o currículo ou a maneira como o professor transmite o conhecimento. O novo paradigma transporta o professor do papel de instrucionista (aquele que instrui o aluno) para construcionista, onde o aluno elabora o conhecimento cooperativamente.

Desta forma, o computador jamais substituirá o professor, pois para o desenvolvimento do conhecimento, sempre será necessário à intervenção do professor.

Segundo o RCN (1998), uma das funções das instituições de ensino é inserir o aluno nos contextos sociais, ambientais, culturais e nas interações e práticas sociais, buscando 


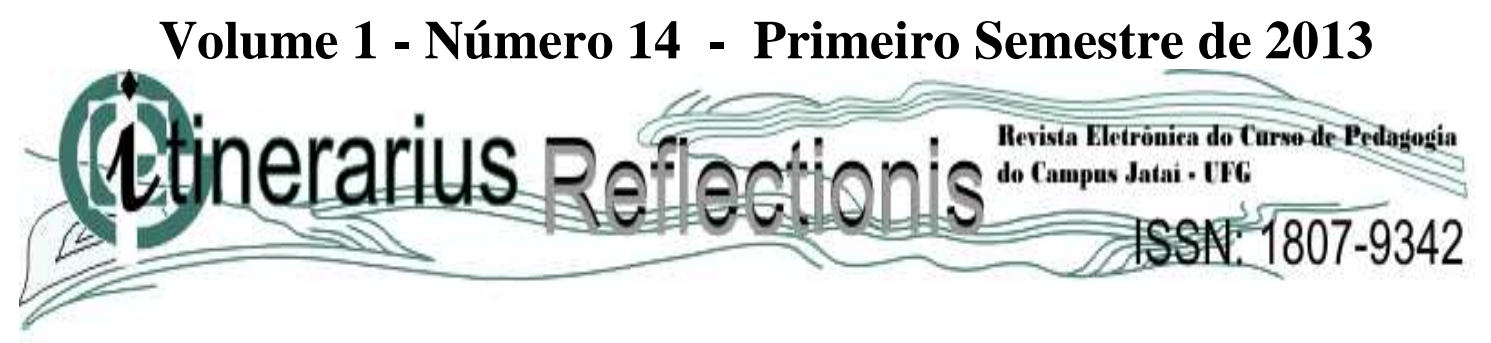

fornecer elementos para diversas linguagens e o contato com diversos conhecimentos. Assim, a criança construirá sua própria identidade.

\begin{abstract}
A instituição de educação infantil deve tornar acessível a todas as crianças que a freqüentam, indiscriminadamente, elementos da cultura que enriquecem o seu desenvolvimento e inserção social. Cumpre um papel socializador, proporcionando desenvolvimento da identidade das crianças, por meio de aprendizagens diversificadas, realizadas em situações de interação (RCNs, 1998, Vol1, p. 23).
\end{abstract}

No art. $22^{\circ}$ da Lei de Diretrizes e Bases da Educação - LDB 9.394/96 - dispõe, que: "a educação básica tem por finalidades desenvolver o educando, assegurando-lhe a formação comum indispensável para o exercício da cidadania e fornecer-lhe meios para progredir no trabalho e em estudos posteriores" (BRASIL,1996 p.22).

Para isso a instituições escolares devem proporcionar aos alunos uma formação que os prepare para a sociedade. Sendo assim, deve se organizar para incorporar as novas tecnologias e produtos em seus processos. Para tanto, é necessário propostas que atenda a educação infantil, ou seja, a elaboração de um Projeto Político Pedagógico com metas a cumprir e meios para concretizá-las para que atenda as necessidades da escola/professor/aluno.

Esses objetivos só acontecem quando a escola assumi um modelo contextualizado, resgatando as experiências que o aluno trás, bem como seus valores, tornando as aulas prazerosas e significativas. O professor é peça fundamental neste processo, pois segundo (Padilha 2004), “juntar crianças em uma sala de aula não lhes garante ensino, não lhes garante escola cumprindo seu papel, não lhes garante aprendizagem e, portanto, não lhes garante desenvolvimento" (PADILHA, p. 96).

No Plano Nacional de Educação - PNE - as estratégias a ser alcançadas até 2021 


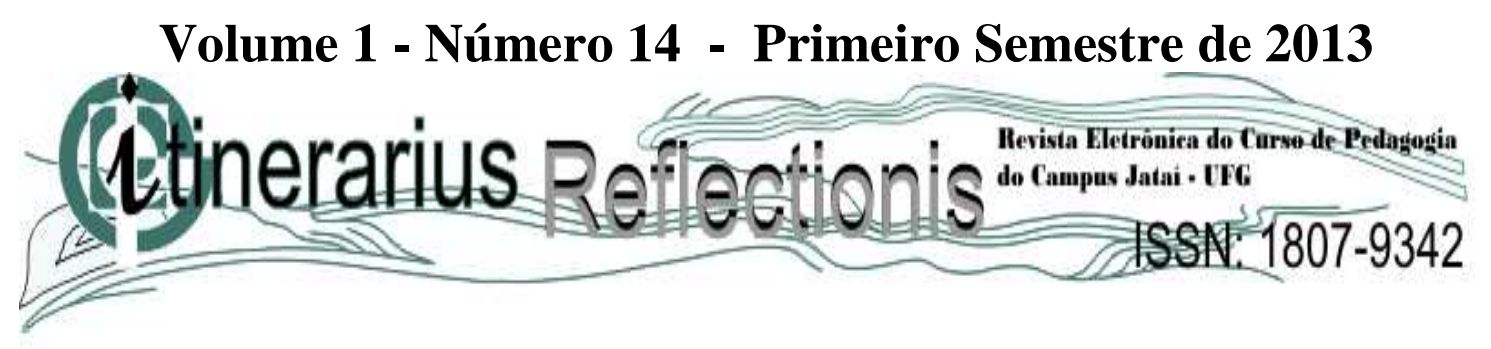

devem ser: Selecionar, certificar e divulgar tecnologias educacionais para o ensino fundamental e médio, assegurando uma diversidade de métodos e propostas pedagógicas. Inserindo o desenvolvimento de tecnologias educacionais e implementando novas práticas pedagógicas.

Saviani (1983), destaca ainda que, "a dimensão política se cumpre na medida em que ela se realiza enquanto prática especificamente pedagógica" (SAVIANI, 1983, p.93).

Se a lei possibilita inovação no ensino, então, a informática pode e deve ser uma ferramenta auxiliar para os conteúdos curriculares, viabilizando a construção do conhecimento, pois quando bem trabalhada, despertar a curiosidade das crianças para descobrir novos caminhos na aprendizagem.

Portanto, existem vários programas que ajudam a desenvolver os trabalhos com os alunos. Para que o objetivo destes programas seja alcançado, é necessário que o professor esteja disposto a se adaptar a nova realidade da escola informatizada. Pois, as informatizações das escolas provocam mudanças que muitas vezes não são compreendidas pelos professores, gestores e funcionários da instituição de ensino. Para Tajra (2000) a escola precisa se adaptar a nova realidade, ou seja, a escola deve manter programa de formação inicial e continuada para o pessoal técnico das secretarias de educação e dos professores.

Segundo Valente (1998), "o computador para ser efetivo no processo de desenvolvimento da capacidade de criar e pensar não pode ser inserido na educação como uma simples máquina de ensinar (VALENTE, 1998, p. 149)". O computador deve ser visto como mudança por todos da instituição através das atividades pedagógicas, quando inseridas na escola como um novo processo tecnológico e jamais como substituição humana. 


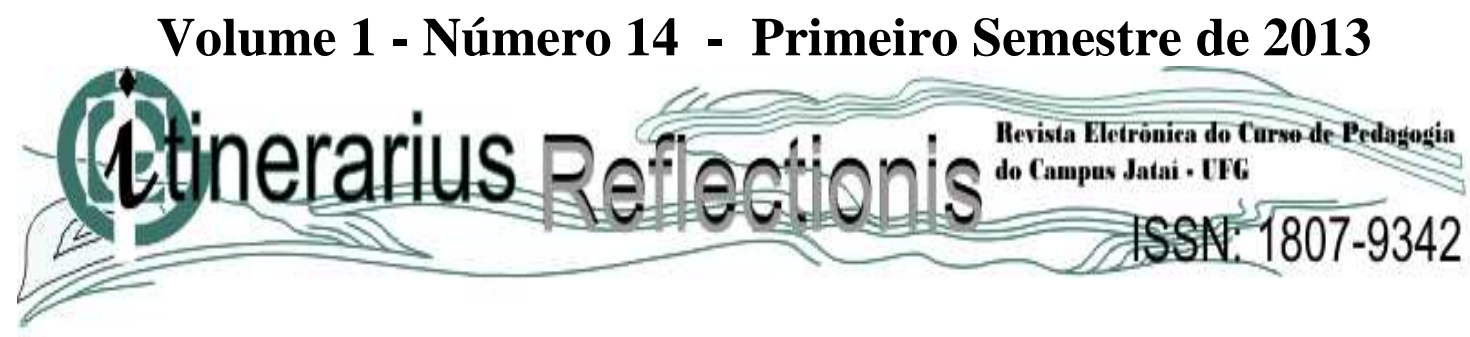

Brandão (1994) complementa que

[...] além dos conhecimentos necessários a uma utilização operativa das diversas estratégias de emprego do computador em atividade didáticopedagógicas, é necessário que os professores desenvolvam capacidades ligadas:

a) à análise dos próprios métodos de ensino, a partir, também, das potencialidades oferecidas pela informática e pelo uso do computador;

b) à avaliação das vantagens e limites existentes;

c) ao exame dos efeitos da nova postura e das novas tecnologias no ensino e na motivação dos estudantes;

d) à utilização crítica de programas de manipulação de informação para facilitar suas atividades diárias e desenvolver, nos estudos, habilidades de pesquisa e de comunicação. (BRANDÃO, 1994, p 35).

Sendo assim, o professor deve procurar saber qual o conhecimento que a criança traz sobre informática. Com essa informação em mãos, o mesmo, pode buscar caminhos para as atividades pedagógicas acompanhando o processo tecnológico. Algumas crianças se sentirão a vontade, pois já estão inseridas no mundo da tecnologia e outras terão receio quanto ao manuseio do equipamento, mas com o desenvolver das atividades pedagógicas junto aos softwares a criança perceberá a facilidade do manuseio do equipamento.

O uso dos novos recursos tecnológicos apresenta como resultado a criação de ambientes construtivistas de aprendizagem, por meio do uso de linguagem de programas. Diversas experiências realizadas com o uso de alguns programas mostraram que as linguagens de programação podem constituir-se em poderosas ferramentas de ensino/aprendizagem, no sentido em que ao ensinar a tartaruga - um ambiente de aprendizagem "logo" - a realizar determinadas atividades educacionais, o aluno é obrigado a construir o seu próprio conhecimento e a organizar suas ideias.

Para uma utilização eficiente e completa de um jogo educativo computadorizado é 


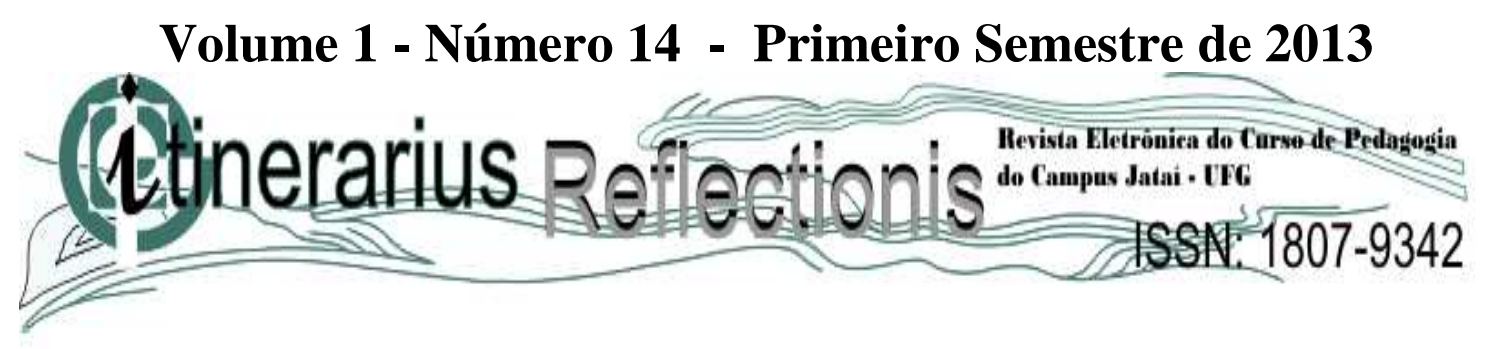

necessário realizar uma análise consistente sobre o mesmo, verificando tanto aspectos pedagógicos como aspectos de qualidade de software.

O computador, ou melhor, os softwares por meio de jogos e simuladores, podem apresentar as atividades proposta pelo currículo regular de ensino, com outras características que não são permitidas no papel, como por exemplo: a animação, som e manutenção de controle da performance do aprendiz, facilitando o processo de administração das lições e possíveis programas de remediações.

\section{Softwares educativos}

Os jogos educativos no computador são inovadores, pois podem ser como simulações interativas nas atividades de sala de aula onde as estratégias de jogo são integradas e o objetivo educacional é alcançar o desenvolvimento cognitivo do educando. $\mathrm{O}$ aluno tem a sensação de que aprender é divertido. Segundo os estudos de Ronca (1986), os jogos e simuladores não são brinquedos que o educador utiliza somente para criar um clima gostoso em sala de aula ou apenas variar as estratégias, pelo contrário, eles não só devem fazer parte do planejamento de ensino, como também, devem visar uma situação de aprendizagem muito clara e específica, exigindo certos procedimentos para a sua elaboração e aplicação.

Os softwares educacionais de simulação se classificam quanto aos níveis de fidelidade, a união de hipertexto (são textos em formato digital cujo nome se dá hiperlinks ou links) e multimídia (combinação de textos, arte gráfica, som, imagem, animação, vídeo, transmitido e manipulado pelo computador).

Conforme os estudos de Mendes, 1992, as classificações podem receber as seguintes categorias: estáticas ou interativas. A simulação estática não envolve o aluno, ou seja, o fenômeno é representado ou simulado e os alunos são expectadores passivos desse fenômeno. A simulação interativa fornece algumas situações previamente definidas, mas ao 


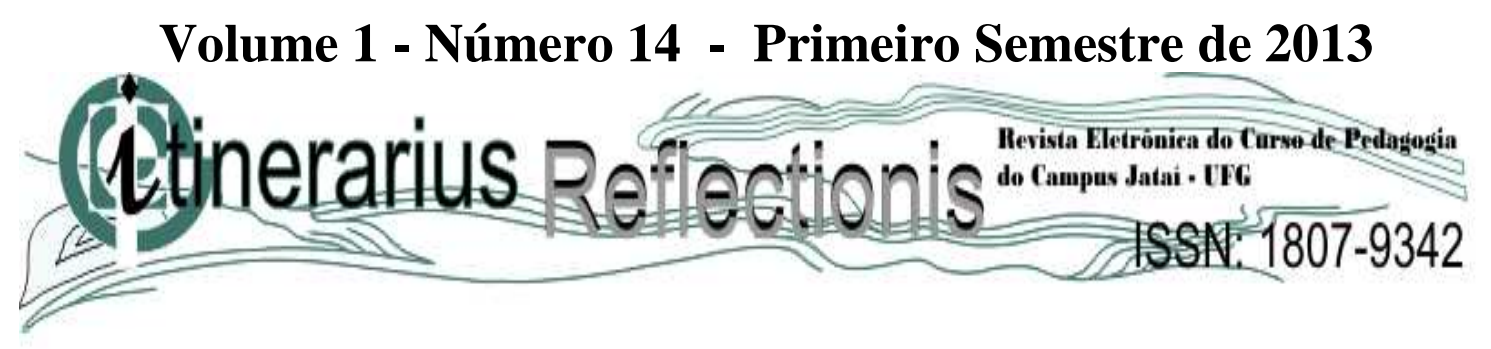

mesmo tempo encoraja o aprendiz a elaborar suas hipóteses que serão validadas no próprio processo de simulação.

Portanto, a simulação por si só não cria a melhor situação de aprendizado. Esse raciocínio é confirmado por Valente, (1999), quando afirma que:

\begin{abstract}
A aprendizagem pode ocorrer basicamente de duas maneiras: a informação é memorizada ou é processada pelos esquemas mentais e esse processamento acaba enriquecendo esses esquemas. Neste último caso, o conhecimento é construído. [...] O computador pode ser um importante recurso para promover a passagem da informação ao usuário ou facilitar o processo de construção de conhecimento. No entanto, por intermédio da análise dos softwares, é possível entender que o aprender (memorização ou construção de conhecimento) não deve estar restrito ao software, mas à interação do aluno-software. [...] Assim, a análise dos softwares educacionais, em termos da construção do conhecimento e do papel que o professor deve desempenhar para que esse processo ocorra [...], cada um dos diferentes softwares usados na educação [...] podem favorecer, de maneira mais ou menos explícita, o processo de construção do conhecimento [...] É isso que deve ser analisado, quando escolhemos um software para ser usado em situações educacionais. (Valente, 1999, p.89.)
\end{abstract}

As simulações também podem ser interdisciplinares, um exemplo é o ambiente Logo que propicia ao aluno o pensar e o repensar, a resolver problemas e a corrigir seus erros. No Logo o erro é tratado como tentativa de acerto, podendo construir o cognitivo da criança de forma prática, clara, oferecendo ao aluno um auto-aprendizado. Neste ambiente o aluno é colocado em várias situações que possa desenvolver hipóteses, testá-las e assim analisar o resultado. Quando o aluno percebe o erro ele pode mudar.

A característica do ambiente logo é a tartaruga, um animal robótico que é direcionado através de comandos.

O objetivo desse símbolo é de estimular a curiosidade e o interesse da criança para programar a tartaruga. O Logo é utilizado para desenho quando são executados os 


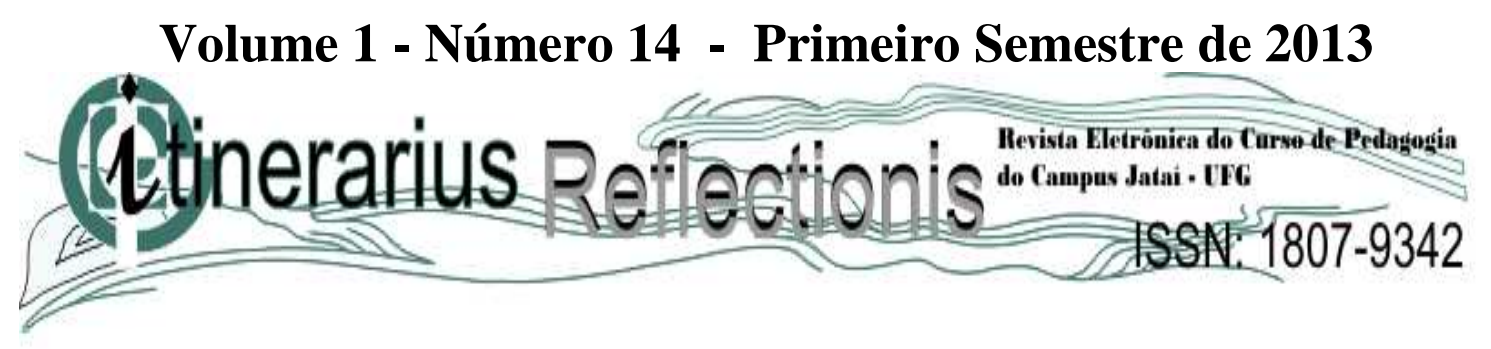

comandos ajudando a criança a assimilar com mais facilidade os passos seguintes para executar a atividade.

Desta forma, o ambiente Logo oferece um novo aprendizado e ajuda no desenvolvimento do aluno em diversos conteúdos curriculares, inclusive na formação psicomotora, no conhecimento matemática, de interpretação textual entre outros.

Uma variação do Logo, chamado de SLOGO oferece comandos que executam operações básicas e avançadas de aritmética, como seno, cosseno, soma, diferença, produto, quociente, potência, raiz quadrada.

Outra é a metodologia que Parpet propõe é carregada de significado lúdico, proporciona à criança uma situação de brinquedo. $\mathrm{O}$ diálogo que se estabelece com a máquina (tartaruga) é naturalmente, uma atividade de brincadeira, em que a criança aos poucos é levada a aprender as noções básicas do sistema Logo. Ao brincar de tartaruga, a criança projeta-se nas ações baseadas na própria experiência de deslocamento no espaço, as quais são similares as da tartaruga da tela. Há aqui um deslocamento dos significados da ação da tartaruga-criança para a tartaruga-da-tela. Isto é, de certa forma, reforça as palavras de Vygotsky (1989).

\footnotetext{
A criança tem capacidade criadora que é muito importante para o desenvolvimento geral e de sua maturação. Criança não se limita em seus jogos a recordar experiências vividas, senão que a reelaboram criticamente, combinando-se entre si e edificando-as com elos novos da realidade de acordo com suas afeições e necessidades (VYGOTSKY, 1989, p.15).
}

Outro programa que pode auxiliar o professor em suas atividades pedagógica é o HagáQuê, desenvolvido para crianças que estão no ensino fundamental. O software busca desenvolver a linguagem e a escrita, no processo de alfabetização. 


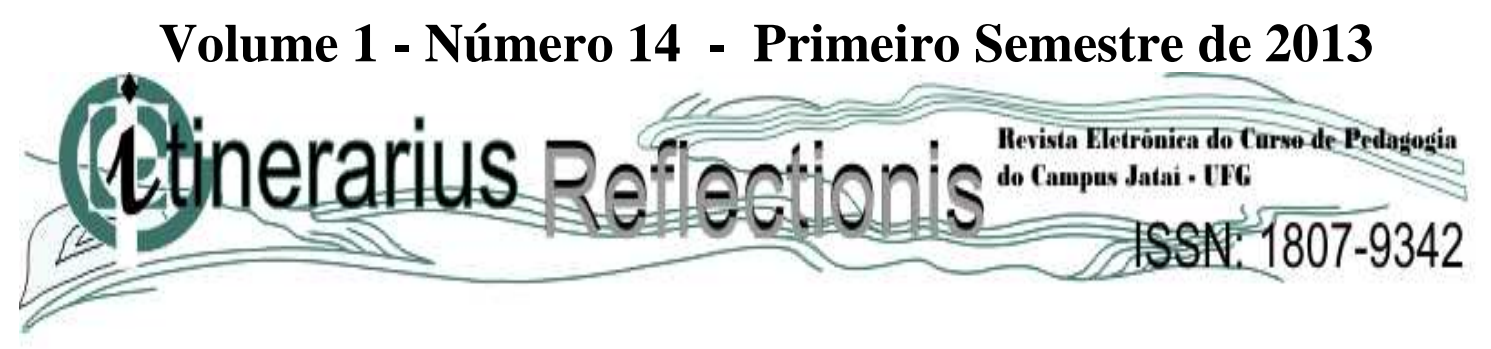

O HagáQuê apresenta uma interface adaptada às limitações e necessidades do usuário. Possui recursos facilitadores que proporciona ao aluno liberdade de expressão, oferecendo a possibilidade de compor os mais diferentes personagens como ocorre nas Histórias em Quadrinhos.

No processo de alfabetização, a criança deve ser levada a dominar diversos registros e funções da linguagem, diversas formas de estruturação discursiva, cada uma relacionada à determinados contextos e finalidades e a certos usos sociais específicos. Uma das atribuições fundamentais do ensino escolar da língua escrita é a oferta de uma diversidade, a mais ampla possível de tipos de textos cuja leitura seja estimulada dentro e fora da sala de aula, como sugerem os Parâmetros Curriculares Nacionais [PCN,1997].

Além disso, as reflexões feitas por Hawad, 1994, apontam que as atividades de produção de texto pelas crianças devem contemplar, ao mesmo tempo, gêneros e formas diferentes, a fim de sensibilizar o aluno quanto à necessidade de adequar seu discurso ao interlocutor, à finalidade do ato de comunicação, ao tipo da mensagem, entre outros fatores.

Entre os gêneros adequados para o trabalho com a linguagem escrita, sugeridos pelos PCN, encontram-se as histórias em quadrinhos. Na disciplina de artes, os quadrinhos estão inseridos em dois blocos de conteúdos: Expressão e comunicação na prática dos alunos em artes visuais, como as artes visuais no fazer do aluno, e no bloco As artes visuais como objeto de apreciação significativa para contato sensível, reconhecimento, observação e experimentação de leitura das formas visuais em diversos meios de comunicação da imagem. Conforme os estudos de Hawad, 1994, as HQs contribuíram para a produção de texto, pois a língua escrita dos quadrinhos é, na verdade, representação da língua falada, não se identificando com as regras da língua escrita em sentido estrito. Nas fases iniciais da aquisição da escrita, a produção da criança tende a ser um reflexo da língua falada, o que se manifesta na referida dependência contextual. 


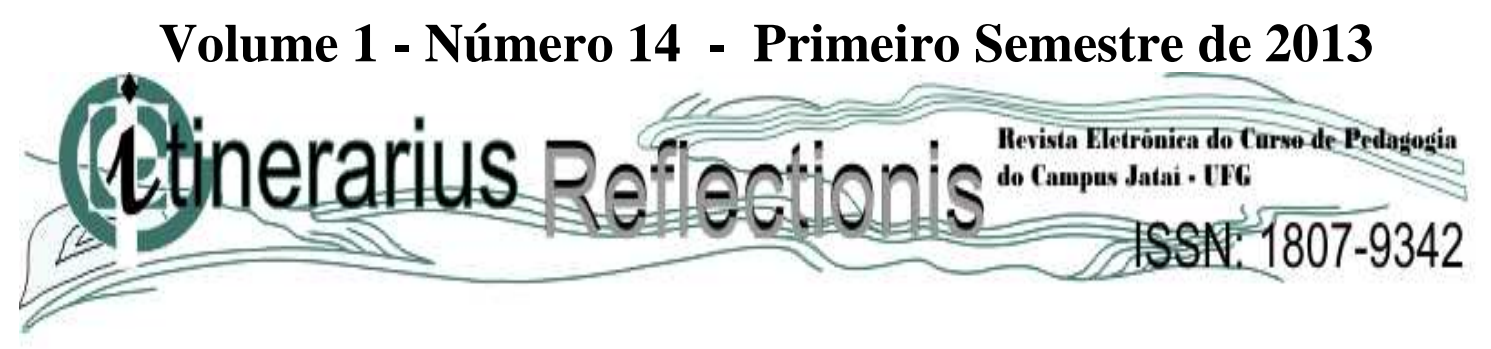

Assim, preocupados com o público alvo, o editor do HagáQuê segue as mesmas linhas já amplamente referendadas pela comunidade educacional. A versão final do HagaQuê deverá oferecer uma interface facilitadora, ou seja, uma interface com elementos que tenham seus significados inferidos facilmente, para que o esforço cognitivo do usuário esteja totalmente voltado para tarefa de edição de sua história, e não para o recurso computacional utilizado. A interface deve ser transparente para o usuário, para que o editor de HQs cumpra seu papel educacional.

A utilização de quadrinhos é positiva no processo de alfabetização devido ao fascínio das crianças pelos personagens, desenhos, onomatopéias, cores etc. A estrutura organizacional do texto desperta a atenção por ser significativa e compreensível para a criança na fase inicial de aprendizagem, já que esta associa duas formas de representação: o desenho e a palavra escrita.

As histórias em quadrinhos são textos narrativos que se caracterizam pela presença de códigos não verbais, ou seja, os próprios recursos gráficos garantem a veiculação das idéias, auxiliadas ou não pela palavra escrita.

Os textos feitos em balões divertem e além de serem atrativos tem uma boa ferramenta que ajudam o professores na escrita e na leitura das crianças em especial daquelas com dificuldade de aprendizagem.

Bim, (2001), afirma que:

Vygotsky observou que, quando uma criança libera seus pensamentos ao desenhar, ela o faz como se estivesse contando uma história, descrevendoa oralmente para outra pessoa, de forma semelhante ao desenvolvimento de uma história em quadrinhos (BIM, 2001, apud VYGOTSKY, 1991, p. 127).

O HQ auxilia as crianças no desenvolvimento da escrita, pois a linguagem reproduzida 


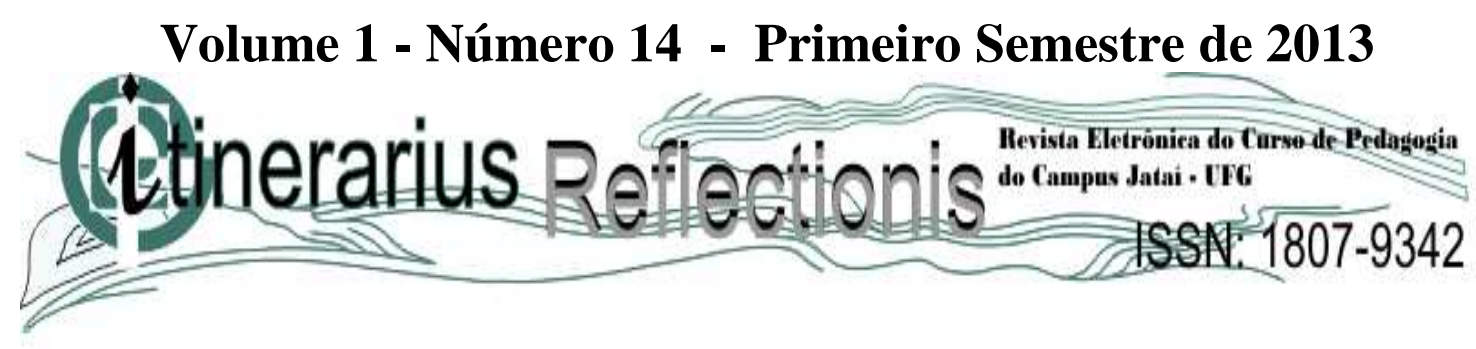

nos quadrinhos é sempre uma representação da língua falada, onde o aluno escreve a história como ele cria em seu imaginário, usando sempre dos recursos lingüístico como a onomatopéia, para reproduzir seu texto.

Sendo assim, o planejamento da aula com o HagáQuê o professor pode explorar a oralidade e a escrita nos balões das histórias em quadrinhos. Cabe ao professor planejar a aula antes de usar o software no laboratório. É necessário que defina o objetivo a ser atingido antes de cada aula.

Logo, a escolha de um ambiente que permita a manipulação de imagens de forma prática e simples é muito importante para a aprendizagem (Frizzo, 2001). Por estes motivos, a utilização de histórias em quadrinhos em sala de aula pode proporcionar, além de facilidades de compreensão de conteúdos, o desenvolvimento da criatividade por parte dos alunos, pois as apresentações em figuras são mais interativas, levando a um melhor desempenho da memória (Frizzo, 2001).

Bullough, (2000), comprovou em seus estudos que as histórias em quadrinhos deixaram de ser vistas somente como instrumento de diversão e passaram a integrar o material pedagógico de escolas, não apenas de educação infantil, mas também na de jovens e adultos, por ser de fácil leitura atrai crianças e adultos.

\section{TUXPAINT}

Os softwares educacionais foram criados com o objetivo de facilitar o aprendizado e possibilitar a autoconfiança na criança. Desta forma, o Software TuxPaint que, por sua interação com o usuário, permite um melhor aproveitamento pedagógico, pode ser utilizado numa perspectiva construtivista, na forma de tutorial.

TuxPaint é um software que tem uma interface simples e acessível. No dicionário de termos técnicos informáticos a definição de Interface quer dizer: "Conexão entre dois dispositivos em um sistema de computação. Esse termo é também usado para definir o 


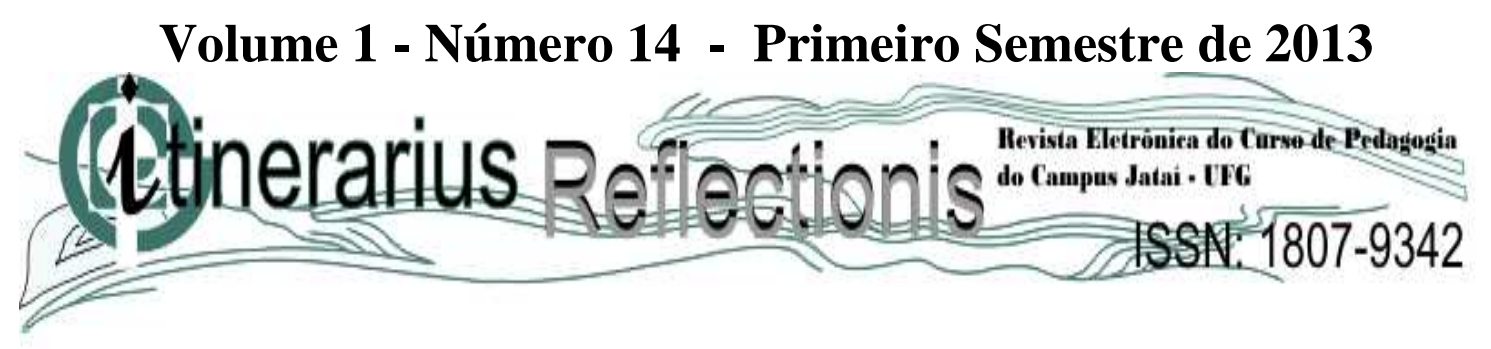

modo (texto ou gráfico) de comunicação entre o computador e o usuário". (Dicionário inFormal, 2009, p. 81).

Levy (1999) afirma ser "todos os aparatos materiais que permitem a interação entre o universo da informação digital e o mundo ordinário" (LEVY, 1999, p. 37). Já Moran (1999) define que "a interface de usuário deve ser entendida como sendo a parte de um sistema computacional com a qual uma pessoa entra em contato físico, perceptivo $e$ conceitualmente" (MORAN, 1999, p.428).

Para Norman, (1988), a tendência em design de interface é oferecer recursos simplificados, mas bem dirigidos. Os programas devem oferecer um ambiente simples oferecendo poucas opções para não inibir a criança principalmente as que estão em fase de alfabetização. Mesmo simplificado, oferece todos os recursos para desenvolver as atividades propostas pelo professor.

O software fornece uma tela em brando com uma variedade de ferramentas que auxiliam no desenvolvimento da criatividade do aluno. Proporcionando uma interface com efeitos sonoros para as ferramentas, como lápis ou a borracha, que faz o barulho de apagar quando é usada, e ainda por cima uma versão animada do Tux, um pingüim mascote ensinando algumas boas dicas. Também há o recurso que permite à criança aplicar efeitos como preenchimento, clareamento, negativagem e espelhamento às imagens.

Mesmo diante dos diversos recursos que o programa oferece, é preciso que o professor analise, qual será o que se adapta no desenvolvimento das atividades propostas, para o conteúdo aplicado. A escolha deve partir da necessidade do professor, para que o planejamento do conteúdo a ser trabalhado possa alcançar os objetivos proposto para a aula. 


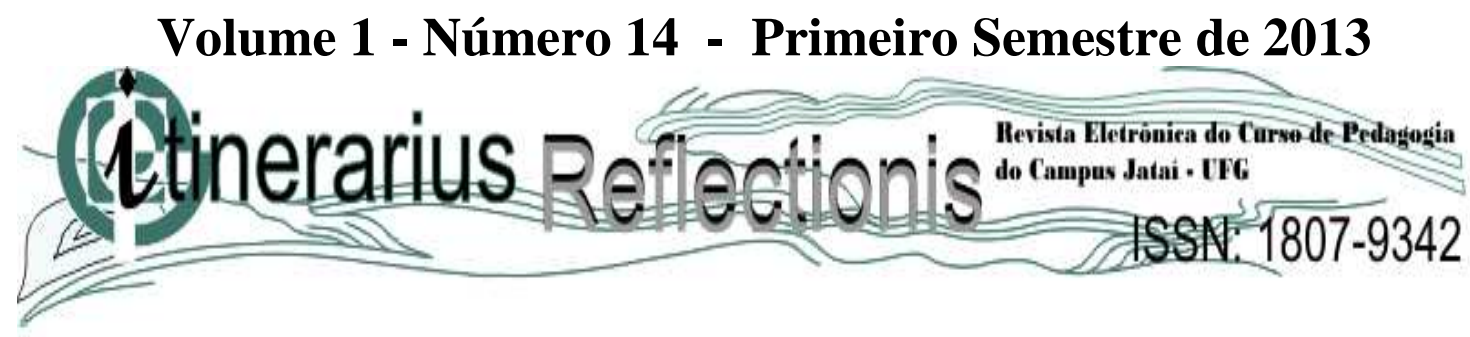

Marisa Lucena (Lucena,98. p.4), e outros autores define o "software educacional" como aqueles que podem ser usados para algum objetivo educacional. Rosa Viccari assim define:

Software Educacional é um programa que visa atender necessidades e possui (ou deve possuir) objetivos pedagógicos. Todo software pode ser considerado educacional, desde que sua utilização esteja inserida num contexto e numa situação de ensino-aprendizagem, onde existe uma metodologia que oriente o processo (VICCARI, 96. p.13).

Em síntese, as grandes maiorias de software encontrado no mercado podem ser utilizados para apoiar o professor nas atividades curriculares. Podendo ser um recurso didático para exploração de determinado tema com os alunos.

\section{CONSIDERAÇÕES FINAIS}

A tecnologia tem auxiliado o homem em quase todas as suas atividades diárias, com o auxílio das redes mundiais de computadores. Em quase todos os lugares possuem um aparelho de computador e a cobertura da internet.

Com base nessa concepção a educação para alcançar seus objetivos, tais quais, de fornecer elementos para diversas linguagens e o contato com diversos conhecimentos, não poderia ficar de fora desta evolução. Sendo assim, à informática deve ser uma ferramenta auxiliar do professor para a aplicação dos conteúdos curriculares, viabilizando a construção do conhecimento com base teórico-metodológico já conhecido.

Para isso, é preciso reconhecer que existem diversos programas voltados para educação, são chamados de softwares educativos. São criados para auxiliar o professor no desenvolvimento de suas aulas, expandindo a didática pedagógica na busca da aquisição do conhecimento.

Nessa reflexão busquei apresentar três destes softwares - Logo, HagáQuê e o Tuxpaint - que auxiliam na elaboração de estratégias precisas para o andamento do 


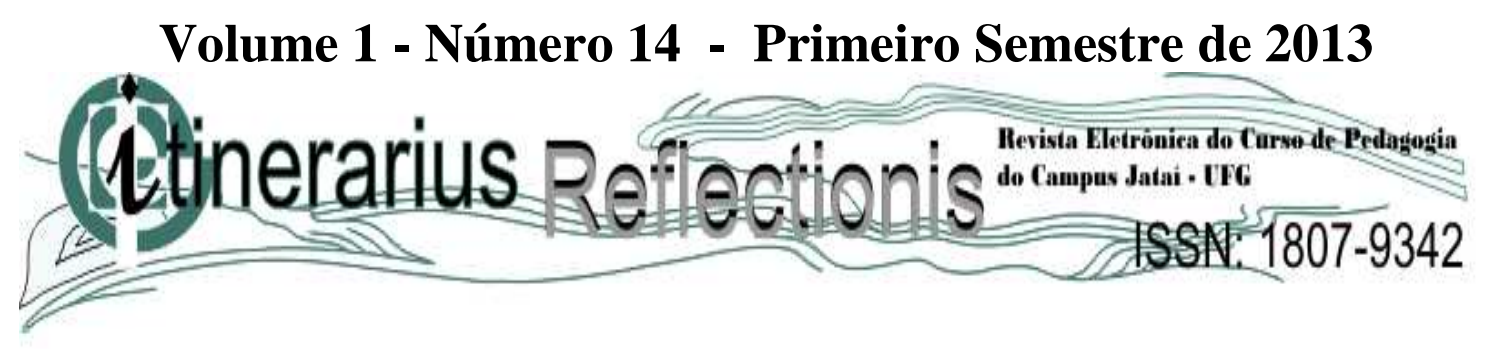

processo de ensino aprendizagem, assim levando a estruturação do conhecimento por parte do educando. $\mathrm{O}$ artigo apresenta de forma clara uma praxe estruturada em softwares educacionais, que favorecem a organização dos conhecimentos escolares, a partir de estruturas internas de conteúdos, tornando a aprendizagem mais significativa.

Por fim, pensar a educação a partir dos elementos computacionais aqui descritos, significa, juntamente, com o uso dos recursos tecnológicos, com ambientes multimídia e interdisciplinar, é garantir a aprendizagem da criança que de fato apresentam como resultado a criação de ambientes construtivistas de aprendizagem, por meio do uso de linguagem de programas. Experiências já realizadas comprovam que alguns programas constituíram-se em poderosas ferramentas de ensino/aprendizagem, pois ao realizar determinadas atividades educacionais, o aluno é obrigado a construir o seu próprio conhecimento e a organizar suas ideias.

Desta forma, as crianças constroem significados a partir de interações, onde cada um é sujeito do processo de aprendizagem, levando o professor à figura de um mediador na interação dos alunos com o objeto do conhecimento.

Assim, nesse contexto, a informática na educação vem se tornando uma excelente maneira de desenvolver o cognitivo do aluno. Com capacidades de levar a criança a construir o conhecimento ao prender a atenção da criança e facilitar a interação, através de um processo de reestruturação cognitiva que permita ao educando ser um agente do seu próprio conhecimento. 


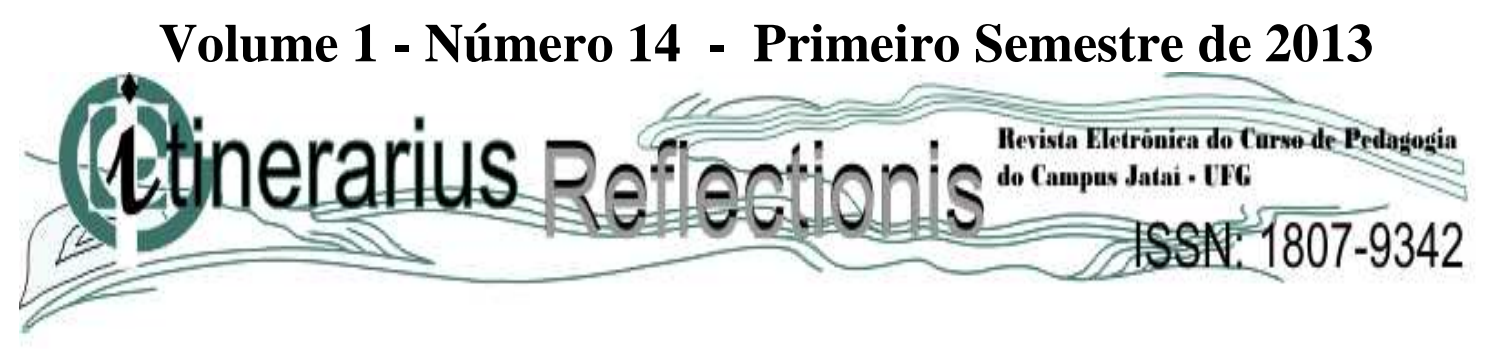

Referências Bibliográficas.

BANDÃO, E. J.R; Teixeira, A. C. Software educacional o complexo domínio dos multimeios. Passo Fundo, RS. Material didático. Universidade de Passo Fundo, 2000.

BRASIL. Ministério da Educação e do Desporto. Secretaria da Educação Fundamental.

Referencial Curricular Nacional para a Educação Infantil. Ministério da Educação e do Desporto, Secretaria da Educação Fundamental. Brasília, MEC/SEF, 1998, Vol1, p. 23.

GRANDES PENSADORES. Revista Nova Escola Especial. São Paulo. Edição Especial, $\mathrm{N}^{\mathrm{o}}$ 19, julho de 2008. p. 32.

LUCENA, M. F.P. O uso das tecnologias da informática para o desenvolvimento da educação. Publicação Técnicas. Rio de Janeiro: COPPE Sistemas/UFRJ, jul 1994. (ES301/94).

LÉVY, Pierre.Cibercultura. São Paulo: Ed. 34 Ltda. 1999 p. 37.

MACHADO, Izaltina de Lurdes - Educação Montessori - de um homem novo para um mundo novo - Editora . Pioneira-Thompson, São Paulo, $1^{\mathrm{a}}$. ed.

MENDES, M.E. O paradigma de hipertexto e o processo de ensino/aprendizagem: uma relação promissora. Tese de mestrado, Coordenação de programas de Pós-graduação e Engenharia COPPE/UFRJ-Universidade Federal do Rio de Janeiro. Rio de Janeiro, 1992. PADILHA, A. M. O que fazer para não excluir Davi, Hilda, Diogo... In: GÓES, M. C. R.; LAPlane, A.L. F. (orgs.). Políticas e práticas de educação 22 inclusiva. Campinas: Autores Associados, 2004.

SAVIANE, Demerval. Pedagogia histórico-crítica:primeiras aproximações. 3 ed. São Paulo: Cortez, 1992.

Educação: do senso comum à consciência filosófica. São Paulo: Cortez, 1993.

TAJRA, S. F. Informática na educação: Novas Ferramentas Pedagógicas para o Professor da Atualidade. Dissertação de Mestrado. 2.ed. São Paulo, Ed. Érica, 2000. 


\section{Volume 1 - Número 14 - Primeiro Semestre de 2013}

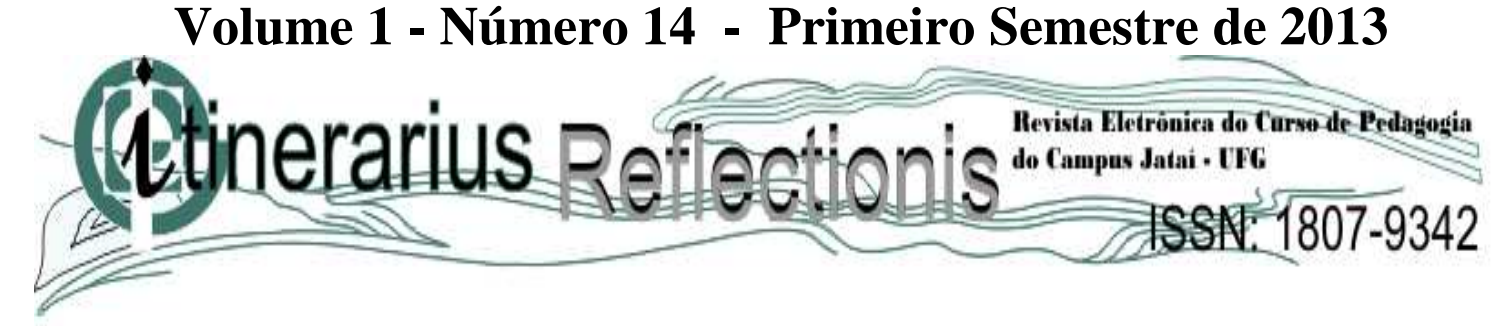

VYGOTSKU, L.S. A Formação social da mente. São Paulo. Martins Fontes, 1984.

VALENTE, José Aramando Valente. Por quê o computador na educação? Brasília:

Ministério da Educação, 2008, Disponível

em:<http://artigos.netsaber.com.br/resumo_artigo_21245 Acesso em: 05 dezembro 2012.> VALENTE, José Armando. O computador na sociedade do conhecimento. São

Paulo: Núcleo UNICAMP, 1999. Disponível em:

<http://www.proinfo.mec.gov.br/upload/biblioteca/111.zip Acesso em: 05 dezembro 2012> VALENTE, J. A. (Org.). Computadores e conhecimento: repensando a educação. 2. ed. Campinas: Unicamp, 1998. p. 149.

VICCARI, Rosa Maria \& Giraffa,L. Sistemas tutores inteligentes: abordagem tradicional X abordagem de agentes. XIII SBIA, Curitiba, PR, 1996. 